\title{
Scientific publishing for greater research impact
}

\author{
Johannes Lehmann · Else K. Bünemann • Marta Camps-Arbestain • \\ Melania Ruiz Esparza Cataño
}

Received: 14 January 2021 / Accepted: 14 January 2021 / Published online: 21 January 2021

(C) The Author(s), under exclusive licence to Springer Nature B.V. part of Springer Nature 2021

The year 2021 brings to Nutrient Cycling in Agroecosystems the transition to a new editor-inchief team. Handing over responsibilities is an appropriate opportunity to contemplate what lessons can be learned to improve the quality and impact of publications. At the same time, it is a good moment to outline a vision for the forthcoming development of the journal. Publishing the highest-quality research requires collaboration between the authors, the editorial team and the referees on a daily basis, regularly supported and guided by the publisher. Scientists will serve in any of these three roles-editor, reviewer, author-on a regular basis. A collegial attitude is needed at any given stage of the publishing process to improve the scientific product. Here, we share some insights from the editorial process for authors to succeed in not only finding approval by editors and referees, but also by readers and users of the scientific

J. Lehmann $(\bowtie)$

Cornell University, Ithaca, NY 14850, USA

e-mail:c1273@cornell.edu

E. K. Bünemann

Department of Soil Sciences, FiBL, 5070 Frick,

Switzerland

M. Camps-Arbestain

Massey University, Palmerston North 4442, New Zealand

M. Ruiz Esparza Cataño

Springer Nature, Dordrecht, The Netherlands insights. We are convinced that the topics addressed in Nutrient Cycling in Agroecosystems are highly relevant not only for the scientific community, but for the future of our planet given the implications that nutrient cycling in agriculture has on food security, climate change, biodiversity, water and air pollution. Regardless of our role in the publishing process, we must strive to improve quality and outreach of our work rather than the sheer quantity of output. With a rather steady average number of publications of around 80 since 1997, the journal has clearly aimed at maintaining quality rather than growth. We hope that these insights prove useful as a guide to better publications in this and other journals.

\section{Lessons learned to improve the quality and impact of publications}

A lack of fit to the scope of the journal remains the most important reason for rejection at an initial editorial screening (Fig. 1). For Nutrient Cycling in Agroecosystems, this mainly concerns a limited duration of the experiments or complete lack of field observations. Editorial decisions about the fit to the scope of the journal taken before manuscripts are sent out to referees will be honored throughout the review process. In general, time investments by referees and editors are important assets of the journal and must be weighed carefully at every step of the process. 


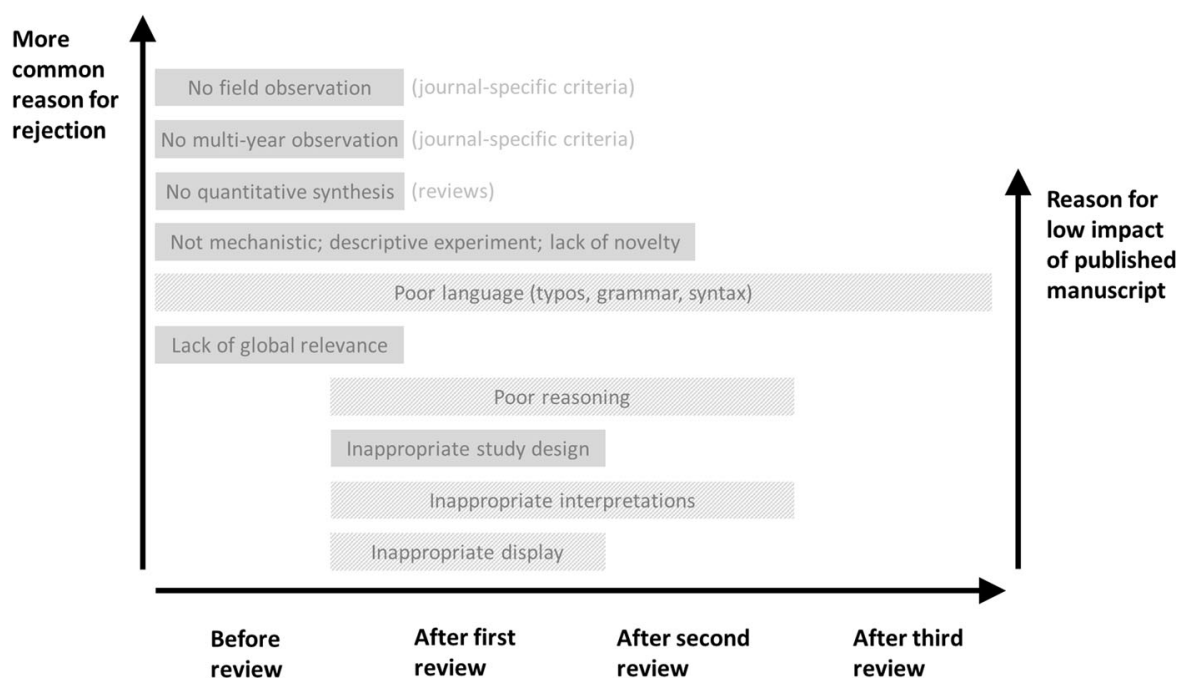

Fig. 1 Reason for rejection and perceived impact of published manuscripts in Nutrient Cycling in Agroecosystems 2015-2020, as a function of how common the reason for rejection is and when it occurs in the review process (for illustration; J.

The most important avoidable reason for rejection lies in a lack of mechanistic and novel insight, often paired with a lack of global relevance. Novelty and broad applicability are indeed hard-won criteria, and go back to asking the right scientific question at the beginning of the experiment. All too often, creativity in the sciences is erroneously perceived as centering around finding an interesting answer to a question that is already known. However, the most difficult aspect is in fact to identify the question and associated gap in our knowledge in the first place. In some instances, this deficiency is only recognized after the first review, but the vast majority of rejections occurs before the manuscript is sent out for peer-review, especially for lack of global relevance.

The review process of a journal can mainly shape the quality of data analysis and writing, as experiments can be redone only to a limited extent at this stage. Therefore, the lessons learned and proffered here extend to the stages in which the research is planned and then carried out. Several approaches are needed throughout planning and conducting experiments, analyzing data and writing the manuscript (Table 1) to arrive at not only a publication that convinces referees but also receives widespread positive reception with readers and serves the wider community. Most time should be spent on identifying the most exciting science question that should be posed with a
Lehmann, personal impression). Hashed boxes indicate criteria that pertain to manuscript preparation rather than the underlying study

global readership in mind. This can be achieved by workshopping the question with colleagues; screening the literature whether the question has already been asked; or making figures without data to anticipate results and the insights gained. During experimentation, it can be transformational to use an iterative approach including trial-and-error; examining preliminary results and adjusting or adding experiments to narrow explanations. At the stage of data analyses and writing, it is important to analyze and visualize the data in various ways; identify different storylines; and focus on the $2-3$ most compelling stories. The most common adjustment recommended in this journal during review is to utilize these $2-3$ stories as subsection titles in the discussion section. Phrasing subsection titles as take-home messages (e.g., "The earth is flat") not only elevates the main points of the paper but also safeguards against interpreting all results and supports the focus on the most interesting and rewarding aspect of a study. Similarly common are editorial and referee requests to re-write conclusions to avoid repeating results and rather to state unique insights on wider implications of the study. The greatest challenge typically poses crafting a short but insightful article title that must avoid starting with vague terms (e.g., impact, comparison, effect) and is most effective when phrased as a message. 
Table 1 Recommendations for greater impact and acceptance rates of scientific publications

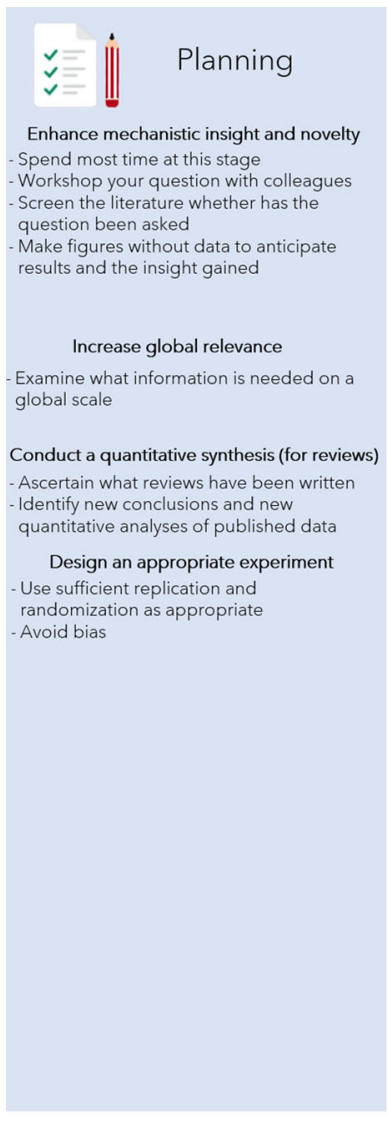

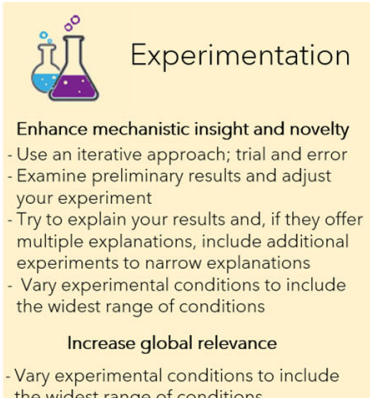

Design an appropriate experiment Randomize sample analyses

\begin{tabular}{|c|c|}
\hline Data Analysis & Writing \\
\hline Enhance mechanistic insight and novelty & Enhance mechanistic insight and novelty \\
\hline $\begin{array}{l}\text { Try out many ways to analyze and visualize } \\
\text { the data } \\
\text { - Identify various storylines } \\
\text { Focus on } 2-3 \text { stories that you want to tell }\end{array}$ & $\begin{array}{l}\text { - Identify } 2-3 \text { novel take-home messages } \\
\text { from your study and use those as } \\
\text { subsection titles for your discussion section } \\
\text { - Explain your results mechanistically } \\
\text { - Make use of supplementary online material } \\
\text { for additional method information and } \\
\text { alternative analyses }\end{array}$ \\
\hline Increase global relevance & Increase global relevance \\
\hline $\begin{array}{l}\text { Use continuous axes and models as much } \\
\text { as possible }\end{array}$ & $\begin{array}{l}\text { - Justify the study and interpret data with } \\
\text { global readership in mind (avoid location as } \\
\text { a justification or in title) }\end{array}$ \\
\hline Conduct a quantitative synthesis (for reviews) & Conduct a quantitative synthesis (for reviews) \\
\hline \multirow[t]{5}{*}{$\begin{array}{l}\text { - Conduct quantitative analyses of published } \\
\text { data, preferably using continuous axes } \\
\text { (avoid tables) }\end{array}$} & $\begin{array}{l}\text { - Identify and order the manuscript by main } \\
\text { messages you intend to convey } \\
\text { - Identify research recommendations }\end{array}$ \\
\hline & $\begin{array}{l}\text { Align with journal-specific criteria } \\
\text { - Study guide to authors and published } \\
\text { manuscripts to ascertain suitability for the } \\
\text { journal } \\
\text { Enhance reasoning }\end{array}$ \\
\hline & $\begin{array}{l}\text { - Use specific expression } \\
\text { - Stay close to what the data show } \\
\text { - Clearly indicate what is speculation and list } \\
\text { all likely interpretation }\end{array}$ \\
\hline & Improve language \\
\hline & $\begin{array}{l}\text { Recognize that high-quality writing consists } \\
\text { of avoiding sloppy mistakes (formatting, } \\
\text { typos), poor grammar, both of which can } \\
\text { be addressed by professional editing } \\
\text { services, and syntax that needs to be } \\
\text { addressed by the authors }\end{array}$ \\
\hline Align data with interpretation & Align data with interpretation \\
\hline - Use a diverse set of data display and analyses & $\begin{array}{l}\text { - Interpret only what the data allow; non- } \\
\text { significant differences are equal }\end{array}$ \\
\hline Develop insightful display items & Develop insightful display items \\
\hline $\begin{array}{l}\text { - Align data analyses with the main messages } \\
\text { and display items }\end{array}$ & $\begin{array}{l}\text { - Examine several different ways of displaying } \\
\text { your data }\end{array}$ \\
\hline
\end{tabular}

significantly improve a publication. On the other extreme, language deficiencies are reason for rejection throughout the review process, and indeed the most important reason for rejection after the second review. Author teams that are not able to revise their manuscript to generate a legible and understandable text over the course of two revisions typically instill little confidence that further revisions yield a publishable manuscript. Ideally, the language should be flawless at initial submission, and this includes not only grammar but also syntax and writing style, as well as, sadly, formatting and typos. However, many authors do not recognize these language deficiencies, and publication of important research should in our opinion not be precluded for lack of initial consideration by the journal. However, editors and referees cannot make up for language deficiencies at any stage of the review process, and thus authors have to utilize professional help, through careful selection of the quality of the final product and can help to 


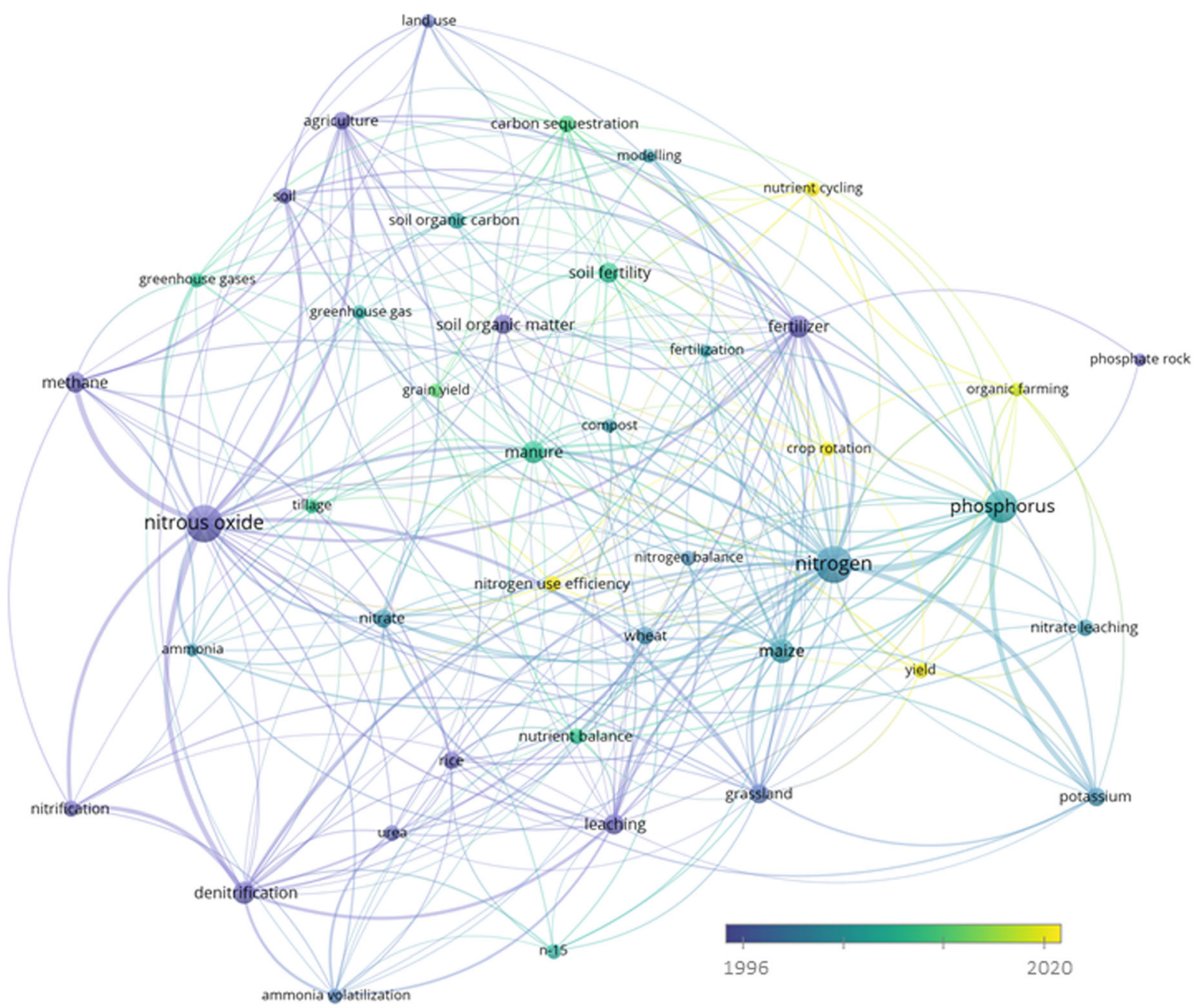

Fig. 2 Visualization of author terms (titles and abstracts) in Nutrient Cycling in Agroecosystems (1996-2020) created with VOSviewer using the function "Co-occurrence". From the total number of publications (1910), 5053 terms were identified and the term occurrence threshold was set to a minimum of 20 , resulting in a display of 42 terms. The size of circles indicates

initial author team as well as professional editorial services.

Journals set important frameworks for successful publishing through their boards. The editorial board is the most important support structure and provides vital input to the editor-in-chief by offering insight to the vision of the journal, promoting the journal among their peers, and/or contributing to peer review as well as serving as guest editors for special issues. Broad disciplinary, geographic, gender, and racial diversity are pivotal to the quality of science that the journal can attract and support. Gender diversity of the board of the number of occurrences of a term throughout the whole period considered. Terms closer to each other co-occur more frequently together. The lines between terms represent cooccurrence links. The stronger the link between two terms, the thicker the line that is displayed. Terms are colored to indicate the variation over time

this journal only increased from 6 to $20 \%$ female members in the last five years, which requires further prioritization and will be addressed by the new editorsin-chief, along with a continuous attention to a more balanced geographical representation.

\section{Outlining a vision for the development of the journal}

An analysis of co-occurrence of author terms in Nutrient Cycling in Agroecosystems from 1996 to 
2000 (Fig. 2) illustrates that the main focus of the journal rests on investigating three nutrients (nitrogen, phosphorus and potassium), their cycling processes (with special attention to various nitrogen emissions, in particular denitrification), and four crops (maize, wheat, rice and grassland). The most important scientific topics were changing only slightly over time as shown by the evolution of key terms during the past 25 years (Fig. 2). While a certain development from more agronomic studies with specific nutrient sources such as phosphate rock or urea towards studies with a greater environmental component can be noticed, overall the topics have remained remarkably constant.

A journal has to remain relevant to its authors and readers, and to nurture the community in order to generate new insights. Interdisciplinarity has been a hallmark of this journal that publishes focused studies on microbiology or biogeochemistry, as well as lifecycle assessments or socioeconomic studies. This allows an unusual breadth of views that benefit publishing exciting special issues that transcend individual disciplines to arrive at new insights with broad political and societal implications. We encourage you to engage with us during this transition of editor-in-chiefs by providing suggestions for special issues and helping us build an even better publishing platform.

The evolution of key words over time (Fig. 2) triggers many questions and ideas for increasing the breadth of the journal. Although there is no doubt that efficient management of nitrogen and phosphorus remains of paramount importance, it would certainly be important to foster a greater diversity of nutrients addressed in this journal, including micronutrients, in view of balanced plant nutrition and their implication in a balanced human nutrition, as well as the management of finite resources. Although some biological processes such as greenhouse gas emissions are already frequent topics in this journal, symbiotic nitrogen fixation and effects of soil enzymes, various soil organisms as well as overall biodiversity on nutrient cycling could be addressed more often. A third area that will be developed further concerns the recycling of nutrients, in order to approach a more circular and more sustainable agriculture. Finally, interactions of nutrient cycling with water availability to plants are becoming more important with climate change and associated implications for desired resilience and resistance of agroecosystems. Hence, we expect this area to grow over the next years, together with technological aspects such as precision farming and remote sensing, as well as the modelling of nutrient cycling at different scales (i.e., within farm, watershed, regional, global scale) to be used as tools for analysis and decision-making. We look forward to developing the journal in this sense together with the editorial board.

\section{Complaince with ethical standards}

Conflict of interest Melania Ruiz Esparza Cataño is an employee of Springer Nature.

Publisher's Note Springer Nature remains neutral with regard to jurisdictional claims in published maps and institutional affiliations. 